\title{
Swarm Intelligence in Power System Planning
}

\author{
Ke Meng, Z.Y. Dong, Yichen Qiao \\ Centre for Intelligent Electricity Networks, The University of Newcastle, Australia \\ Email: ke.meng@uon.edu.au,zydong@ieee.org
}

Received 2013

\begin{abstract}
Power system planning is one of the essential tasks in the power system operation management, which requires in-depth knowledge of the system under consideration. It can be regarded as a nonlinear, discontinuous, constrained multi-objective optimization problem. Although the traditional optimization tools can be used, the modern planning problem requires more advanced optimization tools. In this paper, a survey of state-of-the-art mathematical optimization methods that facilitates power system planning is provided, and the needs of introducing swarm intelligence approaches into power system planning are discussed.
\end{abstract}

Keywords: Power System Planning; Swarm Intelligence

\section{Introduction}

Power system planning plays a significant role in maintaining power system stability and reliability. It determines the right schedule of introducing additional generation facilities, transmission lines, substations, transformers, reactive compensations, and control devices; also it covers the direction of replacement needs with respect to aging existing power system devices, where all of these are directed at increased stability and reliability through market-driven augmentations [1].

Generally speaking, in terms of objectives, the planning issues may be categorized as generation planning and transmission planning; while in term of periods, the planning problems can be classified into short-term planning, mid-term planning, and long-term planning [2]. Generation planning is intended to determine the optimal timing, locations, generation equipments and associated capacities required to satisfy various system constraints and operation conditions, which can maximize profit and minimize risk [1]. Similarly, transmission planning aims to select the best time, siting, and transmission facilities to meet the rising customer demand, which minimizes investment and maintains stability [2]. From planning period point of view, the major purpose of short-term planning is to devise operation plans for power plants or single generating unit so as to ensure the balance of supply and demand [3]. Med-term planning provides the guidance for making market decisions and system operations. Long-term planning ensures adequate generation capacities and delivery capabilities will be available to meet the expected future demand increases.

In a word, planning is one of the most important re- search areas in power system analysis, which needs careful and extensive studies and it should be carried out in a timely and effective manner.

\section{New Challenges}

Nowadays, power industries worldwide have been undergoing profound changes with system deregulations and reconstructions. In particular, the traditional, vertically monopolistic structures have been reformed into competitive markets in pursuit of increased efficiency in electricity productions and utilizations. Along with the introduction of competitive and deregulated electricity markets, many power system problems have become difficult to be analyzed with traditional methods, especially when power system planning issues are involved.

Since the change in the competition environment, the perspectives of power system planning are also change correspondingly. In the traditional vertically-integrated structure, the whole power system is operated by single system and service provider, who owns all the generation and transmission assets. Therefore, when conducting power system planning, the generation and transmission planning can be carried out simultaneously. However, after deregulations, the conventional monopolistic structure has been separated into three independent parts: generation, transmission, and distribution. This separation results in a situation that transmission companies have no direct role in deciding the patterns of power generation and distribution. Furthermore, some investment and operation information about generation and distribution companies becomes business confidential and cannot be obtained by the planner [4]. 
Moreover, the modern power system planning process requires a wide array of input information, such as weather forecasts, load forecasts, market forecasts, expected water supply and fuel price variations. In addition, system constraints, single unit constraints, and various chance constraints, along with other environmental and physical influence, are taken into account. Besides technical information, there are social and governmental organizations to be consulted in the process of planning so as to ensure that every decision is well rounded and completed. All these have made existing problems even more complex. As a consequence, more advanced and effective techniques need to be introduced into planning issues.

\section{Swarm Intelligence}

Swarm intelligence is an artificial intelligence technique involving the study of collective behavior in decentralized system, which is made up by populations of simple individuals interacting locally with each other and with external environment [5-8]. Several examples of these systems can be found in the nature, for example, colonies of ants, flocks of birds, schools of fish, groups of bees, packs of wolves, and so on. An interesting phenomenon of swarms is that collective swarm behavior can emerge on a global scale even when all individuals have only a restricted view of the system and interactions between individuals and their environment occur only on a local scale [9]. Owning to these outstanding characteristics, the principles of swarm behavior have been studied extensively and been widely applied into many fields. Computational swarm intelligence is the algorithmic models that imitate the principles of large groups of simple swarm individuals working together to achieve a goal through self-learning, self-adjusting, and mutual cooperation manners. These algorithms have shown to be able to adapt well in changing environments, and are immensely flexible and robust $[8,10]$. Two of the computational swarm intelligence techniques are ant colony optimization (ACO) [11] and particle swarm optimization (PSO) [6]. In the next section, these two swarm intelligence algorithms will be discussed in detail.

\subsection{Ant Colony Optimization (ACO)}

ACO is a metaheuristic inspired by the foraging behavior of ants [12-14]. In order to find the shortest path from the nest to food source, ant colonies exploit a positive feedback mechanism: they use a form of indirect communication called stigmergy, which is based on the laying and detection of pheromone trails $[15,16]$. These ants deposit pheromone on the ground in order to mark some favorable path that should be followed by other members of the colony [13]. ACO takes inspirations from the collec- tive behavior of ants and exploits a similar mechanism for solving optimization problems. In ACO, firstly colonies of artificial ants with given size are generated, and each ant denotes a potential solution, whose performance is measured based on a quality function. Many different paths can be constructed by ants walking on the graph, and these paths encode the target problem. The cost of the generated paths is used to modify the pheromone left by ants, and therefore to bias the generation of further paths towards promising regions of the search space $[17,18]$. Among these feasible paths, ACO attempts to find the one with minimum cost.

\subsection{Particle Swarm Optimization (PSO)}

PSO is a heuristic algorithm developed in [19-21].The algorithm is inspired by the social behavior of a bird flock. It has been found to be successful in a wide variety of optimization tasks. In PSO, each solution is a bird in the flock and is referred to as a particle, which denotes a candidate solution to the optimization problem. The birds in the population evolve their social behavior and accordingly their movement towards a destination. In a PSO system, each particle flies through the multidimensional search space, adjusts its position in search space according to its own experience and that of neighbor particles. A particle makes use of the global best position which the current particle has visited so far, as well as the population best position which the entire population has found so far and the process repeats until the swarm reaches a desired destination. The effect is that particles fly toward a minimum, while still searching a wide area around the best solution. The performance of each particle is measured by using a predefined fitness function, which encapsulates the characteristics of the optimization problem. Two parameters inertia weight and constriction factor are used to control over the previous velocity of the particles [22]. In short, PSO is characterized as a simple heuristic of well balanced mechanism with flexibility to enhance and adapt to both global and local exploration abilities, which gains lots of attention in power system applications [23].

\section{Power System Planning}

In this section, a survey of state-of-the-art mathematical optimization approaches that facilitates power system planning is provided and the merits and needs of introducing swarm intelligence methods into power system planning are discussed.

\subsection{Generation Expansion Planning}

Generation expansion planning is intended to determine the locations, capacities, and expected operations of gen- 
eration plants required to satisfy various requirements and constraints imposed by future expectations and forecasting conditions, which is to be done in a manner that maximizes profits and minimizes risks [1],[24]. Mathematically, the consequent typical generation planning challenge can be expressed as a large-scale, non-linear optimization problem with the objectives of maximizing profits and minimizing risks subject to a set of complicated constraints.

To solve the complicated issues of generation expansion planning, different mathematical methods have been suggested and reported. The initial work started in [25], where a linear programming method was applied to necessitate the linear approximation of objective function and various constraints. Then linear programming model was further enhanced to address the increasingly complex planning issues with multi-objectives [26]. An extensive study of the applications of linear programming methods in power system was given in [27]. Linear programming methods are fast and reliable, but the main drawback is that they are associated with the piecewise linear cost approximation. Another great alternative for generation planning is nonlinear programming methods [28]. However, nonlinear programming methods have a problem of algorithm convergence and complexity. Along with the ever expanding large-scale interconnection of modern power network, both linear programming and nonlinear programming techniques were not adequate for most applications until dynamic programming appeared, which overcame some limitations and received wide acceptance [29]. In general dynamic programming based methods have the advantage over the other techniques, in that, nonlinearity in project capital costs and engineering constraints, sophisticated techniques of production costing such as probabilistic simulation, and an adequate modelling of the reliability of the system during its future stages, can all be more adequately accounted for [30,31]. However, the curse of dimensionality problem of generation expansion planning afflicts the method of dynamic programming particularly severely [32,33]. In many cases, the mathematical equations involved have to be simplified or decomposed in order to obtain possible solutions because of the limited capability of existing mathematical approaches [34,35].

Recently, the advent of global optimization techniques provides another tool for solving power system generation expansion planning problems and satisfactory performance has been reported in a number of references. Typical modern heuristic methods include evolutionary programming (EP) [36], simulated annealing (SA) [37], genetic algorithm (GA) [33,38-42], immune algorithm (IA) [43], PSO [44,45], and composite method [46]. Although the heuristic methods do not always guarantee discovering globally optimal solutions in finite time, they often provide a fast and reasonable solution. Generally speaking, each method has its own merits and drawbacks. Many attempts try to merge some of the individual implementations together into a new algorithm, so that it can overcome individual disadvantages and benefit from each others' advantages. Extensive reviews and comparisons of these techniques in power system generation expansion planning are given in [47-49]. Based on the experience, when compared with other methods, the PSO is computationally inexpensive in terms of memory and speed. The most attractive features of PSO could be summarized as: simple concept, easy implementation, fast computation, and robust search ability [50].

\subsection{Transmission Expansion Planning}

Transmission lines are key components in a power system, especially where system stability and reliability analysis is concerned. In a deregulated electricity market, transmission network service providers make possible the required competitive environment for the market participants. Therefore, as the market grows, transmission planning should be carried out in a timely and effective manner. In a competitive market, such planning is mainly driven by market needs, with the proviso that certain constraints, such as reliability, security, economic considerations, and regulatory rules, are satisfied [51,52]. However, restructuring and deregulation of the power industry have given rise to more and more system uncertainties and have changed the objectives of transmission planning. As a consequence, the process of transmission planning requires an evaluation of the annual load shape and of the cost effectiveness and financial performance of programs and plants, together with an analysis of product attributes, profitability niches, delivery preferences, and investment risks [53]. The intention of such planning is to minimize revenue requirements, meet customer needs, as well as maximize network profits [53,54]. Following these changes, new approaches and action criteria are demanded. These should not only consider the traditional constraints, but they should also promote fair competition in the electricity market as well as ensuring certain levels of reliability.

Transmission expansion planning is a complex multiperiod, multi-objective optimization problem. In previous research, as far as optimization approaches used for transmission expansion planning, the linear programming was most frequently applied [55-58]. Since the transmission expansion planning problem is essentially of a discrete nature, it can be defined via a mixed-integer programming formulation. The applications of mixed-integer programming methods can be found in [59-64]. Dynamic programming method [65] can also been applied to this problem. Similar as generation expansion planning, the artificial intelligence based methods also pro- 
vide perfect options for transmission expansion planning. Technical references can be classified according to the methodologies used to solve the problem, which includes expert systems [66] and fuzzy theory [67]. Recently, different heuristic methods have been proved to be effective with promising performance, such as SA [68,69], tabu search (TS) [70], GA [71-73], differential evolution (DE) differential evolution (DE) [4,74], and PSO [75,76].

\subsection{Planning with Distributed Generation and Renewable Energy resources}

Today, more and more renewable energy resources are being built up and connected to the power grids at transmission as well as distribution levels. Large scale wind farms are connected to transmission networks and are so far the largest renewable generation source except hydro power generations. Planning of wind farms requires significant amount of studies including the conventional generation connection studies as well as very expensive wind farm planning itself. Normally to connect a wind farm, significant historical wind resource data are required to evaluate the suitability of the wind farm site. Once the site is selected, further optimization planning is required to design the exact scheme of the wind farm so as to maximize the energy output of wind power. This is normally a multi-objective, constrained, highly nonlinear problem. Computational intelligence such as PSO and DE can be used to solve the optimization problem in designing the wind farms, $[77,78]$. At distribution level, the increasing penetrations of distributed renewable generation can potentially cause problems with some feeders. The common problems are protection system design and reactive power support issues with such heavily DG connected feeders. Planning of DGs and power quality control devices such as STATCOM is another complex optimization problem, and evolutionary computation can be used in the planning as well, $[79,80]$.

\section{Conclusions}

Owning to these outstanding characteristics, the swarm intelligence techniques have been studied extensively and have been widely applied in many fields. In general, the swarm intelligence techniques can be used to solve the nonlinear, discontinuous, constrained, optimization problem. In this paper, a comprehensive survey of stateof-the-art mathematical optimization methods that facilitates power system planning is provided; the importance of introducing swarm intelligence methods into power system planning is discussed.

\section{REFERENCES}

[1] F. F. Wu, Z. Yen, Y. H. Hou and Y. X. Ni, "Applications of AI Techniques to Generation Planning and Investment,” 2004 IEEE Power Engineering Society General Meeting, Vol. 1, 2004, pp. 936-940.

[2] G. Y. Yang, "Applying Advanced Methods to Power System Planning Studies,” Ph.D. thesis, the University of Queensland, Brisbane, Australia, Oct. 2008.

[3] A. Mazer, "Electric Power Planning for Regulated and Deregulated Markets,” IEEE Press, Wiley Inter-science, 2007.

[4] J. H. Zhao, Z. Y. Dong, P. Lindsay and K. P. Wong, "Flexible Transmission Expansion Planning with Uncertainties in an Electricity Market," IEEE Transactions on Power Systems, Vol. 24, No. 1, 2009, pp. 479-488. doi.org/10.1109/TPWRS.2008.2008681

[5] E. Bonabeau, M. Dorigo and G. Theraulaz, "Swarm Intelligence: From Natural to Artificial Systems,” 1st ed, London, U.K.: Oxford Univ., 1999.

[6] J. Kennedy, R. Eberhart and Y. Shi, "Swarm Intelligence," 1st ed. San Mateo, CA: Morgan Kaufmann, 2001.

[7] A. Engelbrecht, "Fundamentals of Computational Swarm Intelligence” 1st ed. New York: Wiley, 2005.

[8] A. Engelbrecht, X. Li, M. Middendorf and L.M. Gambardella, "Editorial Special Issue: Swarm Intelligence," IEEE Transactions on Evolutionary Computation, Vol. 13, No. 4, 2009, pp. 677-680. doi:10.1109/TEVC.2009.2022002

[9] D. Merkle and M. Middendorf, "Swarm Intelligence and Signal Processing," IEEE Signal Processing Magazine, Vol. 25, No. 6, 2008, pp. 152-158. doi:10.1109/MSP.2008.929839

[10] M. G. Hinchey, R. Sterritt and C. Rouff, “Swarms and Swarm Intelligence,” Computers, Vol. 40, No. 4, 2007, pp. 111-113. doi:10.1109/MC.2007.144

[11] M. Dorigo and T. Stützle, "Ant Colony Optimization," Cambridge, MA: MIT Press, Vol. 3172, 2004, pp. 1-12. doi:10.1007/b99492

[12] S. Goss, S. Aron, J. L. Deneubourg and J. M. Pasteels, "Self-Organized Shortcuts in the Argentine Ant," Naturwissenschaften, Vol. 76, No. 12, 1989, pp. 579-581. doi:10.1007/BF00462870

[13] M. Dorigo, M. Birattari and T. Stützle, “Ant Colony Optimization: Artificial Ants as a Computational Intelligence Technique," Computational Intelligence Magazine on IEEE, Vol. 1, No. 4, 2006, pp. 28-39. doi:10.1109/MCI.2006.329691

[14] T. Stützle and M. Dorigo, “ACO Algorithms for the Quadratic Assignment Problem,” in D. Corne, M. Dorigo, and F. Glover, (eds): New Ideas in Optimization, New York: McGraw-Hill, 1999.

[15] M. Dorigo, V. Maniezzo and A. Colorni, “Ant System: Optimization by a Colony of Cooperating Agents," IEEE Trans. Syst., Man, Cybern. Part-B, Vol. 26, No. 1, 1996, pp. 29-41.

[16] M. Birattari, P. Pellegrini and M. Dorigo, "On the Invariance of Ant Colony Optimization,” IEEE Transactions on Evolutionary Computation, Vol. 11, No. 6, 2007, pp. 
732-742. doi:10.1109/TEVC.2007.892762

[17] M. Dorigo and L. M. Gambardella, “Ant Colony Sstem: A Cooperative learning approach to the traveling salesman problem,” IEEE Transactions on Evolutionary Computation, Vol. 1, No. 1, 1997, pp. 53-66. doi:10.1109/4235.585892

[18] M. Zlochin, M. Birattari, N. Meuleau and M. Dorigo, "Model-based Search for Combinatorial Optimization: A Critical Survey," Annals of Operations Research, Vol. 131, No. 1-4, 2004, pp. 373-395. doi:10.1023/B:ANOR.0000039526.52305.af

[19] J. Kennedy and R. Eberhart, "Particle Swarm Otimization,” IEEE Int. Conf. Neural Network, Perth, Australia, 1995, pp. 1942-1948.

[20] J. Kennedy, "The Particle Swarm: Social Adaptation of Knowledge,” IEEE Int. Conf. Evol. Comput., 1997, pp. 303-308.

[21] J. Kennedy, "Small Worlds and Mega-minds: Effects of NCZGDbourhood Topology on Particle Swarm Performance,” Proc. IEEE Congr. Evol. Comput., Vol. 3, 1999, pp. 1931-1938.

[22] Y. Shi and R. Eberhart, "Parameter Selection in Particle Swarm Optimization," Lecture Notes in Computer Science, Vol. 1447, 1998, pp. 591-600. doi:10.1007/BFb0040810

[23] Y. del Valle, G. K. Venayagamoorthy, S. Mohagheghi, J. C. Hernandez and R. G. Harley, "Particle Swarm Optimization: Basic Concepts, Variants and Applications in power Systems," IEEE Transactions on Evolutionary Computation, Vol. 12, No. 2, 2008, pp. 171-195. doi:10.1109/TEVC.2007.896686

[24] Z. Y. Dong, K. P. Wong, X. Zhou and C. Ziser, "New Issues on Reliable and Efficient Operation of the National Electricity Market of Australia”, Proc DRPT, 2008, Nanjing, China, Apr 2008.

[25] P. Masse and R. Gilbrat, "Application of Linear Programming to Investments in the Electric Power Industry," Management Science, Vol. 3, No. 2, 1957, pp. 149-166. doi:10.1287/mnsc.3.2.149

[26] W. Rutz, M. Becker, F. E. Wicks and S. Yerazunis, "Sequential Objective Linear Programming for Generation Planning," IEEE Transactions on Power Apparatus and Systems, Vol. PAS-98, No. 6, 1979, pp. 2015-2021. doi:10.1109/TPAS.1979.319394

[27] J. K. Delson and S. M. Shahidehpour, "Linear Programming Applications to Power System Economics, Planning and Operations," IEEE Transactions on Power Systems, Vol. 7, No. 3, 1992, pp. 1155-1163. doi:10.1109/59.207329

[28] A. Ramos, I. J. Perez-Arriaga and J. Bogas, “A Nonlinear Programming Approach to Optimal Static Generation expansion Planning," IEEE Transactions on Power Systems, Vol. 4, No. 3, 1989, pp. 1140-1146. doi: $10.1109 / 59.32610$

[29] R. T. Jenkins and D. S. Joy, "Wien Automatic System Planning Package (WASP) - An Electric Utility Optimal Generation Expansion Planning Computer Code,” Oak Ridge National Laboratory, Oak Ridge, TN, ORNL 4945,
1974.

[30] A. K. David and R. D. Zhao, "Integrating Expert Systems with Snamic Programming in Generation Expansion Planning," IEEE Transactions on Power Systems, Vol. 4, No. 3,1989, pp. 1095-1101.doi:10.1109/59.32604

[31] R. Tanabe, K. Yasuda, R. Yokoyama and H. Sasaki, "Flexible Generation Mix under Multi Objectives and Uncertainties," IEEE Transactions on Power Systems, Vol. 8, No. 2, 1993, pp. 581-587. doi:10.1109/59.260824

[32] B. F. Hobbs, “Optimization Methods for Electric Utility resource planning," European Journal of Operational Research, Vol. 83, No. 1, 1995, pp. 1-20. doi:0.1016/0377-2217(94)00190-N

[33] Y. M. Park, J. B. Park and J. R. Won, “A Hybrid Genetic algorithm/dynamic Programming Approach to Optimal Long-term Generation Expansion Planning,” Electrical Power and Energy Systems, Vol. 20, No. 4, 1998, pp. 295-303. doi:10.1016/S0142-0615(97)00070-7

[34] J. A. Bloom, "Long-range Generation Planning Uing Decomposition and Probabilistic Simulation," IEEE Transactions on Power Apparatus and Systems, Vol. PAS-101, No. 4, 1982, pp. 797-802. doi:10.1109/TPAS.1982.317144

[35] Y. M. Park, K. Y. Lee and L. T. O. Youn, "New Analytical Approach for Long-term Generation Expansion Planning Based on Maximum Principle and Gaussian Distribution Function," IEEE Transactions on Power Apparatus and Systems, Vol. PAS-104, No. 2,1985, pp. 390-397. doi:10.1109/TPAS.1985.319054

[36] Y. M. Park, J. R. Won, J. B. Park and D. G. Kim, “Generation Expansion Planning Based on an Advanced Evolutionary Programming," IEEE Transactions on Power Systems, Vol. 14, No. 1,1999, pp. 299-305. doi:10.1109/59.744547

[37] Y. L. Chen, and C. C. Liu, "Interactive fuzzy Satisfying Method for Optimal Multi-objective VAR Planning in Power Systems," IEE Proceedings - Generation, Transmission and Distribution, Vol. 141, No. 6, 1994, pp. 554-560. doi:10.1049/ip-gtd:19941459

[38] Y. Fukuyama and H. D. Chiang, “A Parallel Genetic Algorithm for Generation Expansion Planning," IEEE Transactions on Power Systems, Vol. 11, No. 2, 1996, pp. 955-961. doi:10.1109/59.496180

[39] J. B. Park, Y. M. Park, J. R. Won and K. Y. Lee, “An Improved Genetic Algorithm for Generation Expansion Planning,” IEEE Transactions on Power Systems, Vol. 15, No. 3, 2000, pp. 916-922. doi:10.1109/59.871713

[40] H. Teixeira Firmo, L. F. Loureiro and Legey, "Generation Expansion Planning: An Iterative Genetic Algorithm ApProach,” IEEE Transactions on Power Systems, Vol. 17, No. 3, 2002, pp. 901-906. doi:10.1109/TPWRS.2002.801036

[41] G. B. Shrestha, B. K. Pokharel, T.T. Lie, and S. E. Fleten, "Management of Price Uncertainty in Short-Term Generation Planning," IET Proceedings - Generation, Transmission and Distribution, Vol. 2, No. 4, 2008, pp. 491-504.doi:10.1049/iet-gtd:20070177

[42] H. A. Shayanfar, A. Saliminia Lahiji, J. Aghaei and A. 
Rabiee, "Generation Expansion Planning in Pool Market: a Hybrid Modified Game Theory and Improved Genetic Algorithm,” Energy Conversion and Management, Vol. 50, No. 5, 2009, pp. 1149-1156.

doi:10.1016/j.enconman.2009.02.001

[43] S. L. Chen, T. S. Zhan and M. T. Tsay, "Generation Expansion Planning of the Utility with Refined Immune Algorithm," Electric Power Systems Research, Vol. 76, No. 4, 2006, pp. 251-258. doi:10.1016/j.epsr.2005.06.005

[44] S. Kannan, S. M. R. Slochanal, P. Subbaraj and N.P. Padhy, "Application of Particle Swarm Optimization Technique and Its Variants to Generation Expansion Planning Problem," Electric Power Systems Research, Vol. 70, No. 3, 2004, pp. 203-210. doi:10.1016/j.epsr.2003.12.009

[45] H. Shayeghi, A. Pirayeshnegab, A. Jalili, and H. A. Shayanfar, "Application of PSO Technique for GEP in Restructured Power Systems," Energy Conversion and Management, Vol. 50, No. 9, 2009, pp. 2127-2135. doi:10.1016/j.enconman.2009.04.018

[46] K. P. Wong and Y. W. Wong, "Combined Genetic Algorithm / simulated annealing / fuzzy Set Approach to Short-term Generation Scheduling with Takeor-Pay Fuel Contract," IEEE Transactions on Power Systems, Vol. 1, 1996, No. 1.

[47] J. X. Zhu and M. Y. Chow, “A Review of Emerging Techniques on Generation Expansion Planning," IEEE Transactions on Power Systems, Vol. 12, No. 4, 1997, pp. 1722-1728. doi:10.1109/59.627882

[48] S. Kannan, S. M. R. Slochanal and N. P. Padhy, “Application and Comparison of Metaheuristic Techniques to Generation Expansion Planning Problem,” IEEE Transactions on Power Systems, Vol. 20, No. 1, 2005, pp. 466-475. doi:10.1109/TPWRS.2004.840451

[49] S. Kannan, S. M. R. Slochanal, S. Baskar, and P. Murugan, "Application and Comparison of Metaheuristic Techniques to Generation Expansion Planning in the Partially Deregulated Environment," IET Proceedings - Generation, Transmission and Distribution, Vol. 1, No. 1, 2007, pp. 111-118. doi:10.1049/iet-gtd:20050271

[50] J. B. Park, K. S. Lee, J. R. Shin and K. Y. Lee, “A Particle Swarm Optimization for Economic Dispatch with Non-smooth Cost Functions," IEEE Transactions on Power Systems, Vol. 20, No. 1, 2005, pp. 34-42. doi:10.1109/TPWRS.2004.831275

[51] Z. Xu, Z. Y. Dong and K. P. Wong, “Transmission Planning in a Deregulated Environment," IEE Proceedings Generation, Transmission and Distribution, Vol. 153, No. 3, May 2006, pp. 326-334.

[52] Z. Xu, Z. Y. Dong and K. P. Wong, “A Hybrid Planning Method for Transmission Networks in a Deregulated Environment," IEEE Transactions on Power Systems, Vol. 21, No. 2, 2006, pp. 925-932. doi:10.1109/TPWRS.2006.873134

[53] K. Wissman, "Review of the Ohio Power Siting Board Process," http://www.nrucpartnerships.org.

[54] A. K. David and F. S. Wen, "Transmission Planning and Investment under Competitive Electricity Market Envi- ronment," 2001 IEEE Power Engineering Society Summer Meeting, Vol. 3, 2001, pp. 1725-1730.

[55] J. C. Kaltenback, J. Peschon and E. H. Gehrin, “A Mathematical Optimization Technique for the Expansion of Electric Power Transmission Systems,” IEEE Transactions on Power Apparatus and Systems, Vol. PAS-89, No. 1, 1970, pp. 113-119. doi:10.1109/TPAS.1970.292677

[56] A. Monticelli, A. Santos, M. V. F. Pereira, S. H. F. Cunha, B. J. Parker and J. C. G. Praca, "Interactive Transmission Network Planning Using Least-effort Criterion,” IEEE Transactions on Power Apparatus and Systems, Vol. PAS-101, No. 10, 1982, pp. 3919-3925. doi:10.1109/TPAS.1982.317043

[57] A. Monticelli, A. Santos, M. V. F. Pereira, S. H. F. Cunha, B. J. Parker and J. C. G. Praca, "Interactive Transmission Network Planning Using Least-effort Criterion,” IEEE Transactions on Power Apparatus and Systems, Vol. PAS-101, No. 10, 1982, pp. 3919-3925. doi:10.1109/TPAS.1982.317043

[58] R. Villasana, L. L. Garver, and S. J. Salon, “Transmission net Work Planning Using Linear Programming," IEEE Transactions on Power Apparatus and Systems, Vol. PAS-104, No. 2, 1985, pp. 349-356. doi:10.1109/TPAS.1985.319049

[59] A. dos Santos, Jr. P.M. Franca and A. Said, "An Optimization Model for Long-range Transmission Expansion planning,” IEEE Transactions on Power Systems, Vol. 4, No. 1, 1989, pp. 94-101. doi:10.1109/59.32462

[60] R. Romero and A. Monticelli, "A Hierarchical Decomposition Approach for Transmission Network Expansion Planning,” IEEE Transactions on Power Systems, Vol. 9, No. 1, 1994, pp. 373-380.doi:10.1109/59.317588

[61] R. Romero and A. Monticelli, “A Zero-one Implicit Enumeration Method for Optimizing Investments in Trans-mission Expansion Planning,” IEEE Transactions on Power Systems, Vol. 9, No. 3, 1994, pp. 1385-1391. doi:10.1109/59.336126

[62] G. Latorre-Bayona and I. J. Perez-Arriaga, “Chopin: A Heuristic Model for Long Term Transmission Expansion Planning," IEEE Transactions on Power Systems, Vol. 9, No. 4, 1994, pp. 1886-1894. doi:10.1109/59.331446

[63] N. Alguacil, A. L. Motto and A. J. Conejo, "Transmission Expansion Planning: A Mixed-integer LP Approach," IEEE Transactions on Power Systems, Vol. 18, No. 3, 2003, pp. 1070-1077. doi:10.1109/TPWRS.2003.814891

[64] M. Carrion, J. M. Arroyo and N. Alguacil, "VulnerabilIty-constrained Transmission Expansion Planning: A Stochastic Programming Approach," IEEE Transactions on Power Systems, Vol. 22, No. 4, 2007, pp. 1436-1445. doi.org/10.1109/TPWRS.2007.907139

[65] Y. P. Dusonchet and A. H. El-Abiad, “Transmission Planning Using Discrete Dynamic Optimization,” IEEE Transactions on Power Apparatus and Systems, Vol. PAS-92, No. 4, 1973, pp. 1358-1371. doi:10.1109/TPAS.1973.293543

[66] R. C. G. Teive, E. L. Silva and L. G. S. Fonseca, “A Cooperative Expert System for Transmission Expansion Planning of Electrical Power Systems," IEEE Transac- 
tions on Power Systems, Vol. 3, No. 2, 1998, pp. 636-642. doi:10.1109/59.667393

[67] C. Jaeseok, A. A. El-Keib and T. Tran, “A Fuzzy Branch and Bound-Based Transmission System Expansion Planning for the Highest Satisfaction Level of the Decision Maker," IEEE Transactions on Power Systems, Vol. 20, No. 1, 2005, pp. 476-484. doi:10.1109/TPWRS.2004.840446

[68] R. Romero, R. A. Gallego and A. Monticelli, "Transmission System Expansion Planning by Simulated an-Nealing,” IEEE Transactions on Power Systems, Vol. 11, No. 1, 1996, pp. 364-369. doi:10.1109/59.486119

[69] A. S. D. Braga and J. T. Saraiva, “A Multiyear Dynamic Approach for Transmission Expansion Planning and Long-term Marginal Costs Computation," IEEE Transactions on Power Systems, Vol. 20, No. 3, 2005, pp. 1631-1639. doi:10.1109/TPWRS.2005.852121

[70] R. A. Gallego, R. Romero and A. J. Monticelli, "Tabu search Algorithm for Network Synthesis," IEEE Transactions on Power Systems, Vol. 15, No. 2, 2000, pp. 490-495.doi:10.1109/59.867130

[71] A. H. Scobar, R. A. Gallego and R. Romero, "Multistage and Coordinated Planning of the Expansion of Transmission Systems," IEEE Transactions on Power Systems, Vol. 19, No. 2, 2004, pp. 735-744. doi:10.1109/TPWRS.2004.825920

[72] R. Romero, M. J. Rider and I. deJ. Silva, “A Metaheuristic to Solve the Transmission Expansion Planning," IEEE Transactions on Power Systems, Vol. 22, No. 4, 2007, pp. 2289-2291. doi:10.1109/TPWRS.2007.907592

[73] P. Maghouli, S. H. Hosseini, M. O. Buygi and M. Shahidehpour, "A Multi-objective Framework for Transmission Expansion Planning in Deregulated Environments," IEEE Transactions on Power Systems, Vol. 24, No. 2, 2009, pp. 1051-1061. doi:10.1109/TPWRS.2009.2016499
[74] T. Sum-Im, G. A. Taylor, M. R. Irving and Y. H. Song, "Differential Evolution Algorithm for Static and Multistage Transmission Expansion Planning," IET Proceedings - Generation, Transmission and Distribution, Vol. 3, No. 4, 2009, pp. 365-384. doi:10.1049/iet-gtd.2008.0446

[75] Y. X. Jin, H. Z. Cheng, J. Y. Yan and L. Zhang, "New Discrete Method for Particle Swarm Optimization and Its Application in Transmission Network Expansion Planning," Electric Power Systems Research, Vol. 77, 2007, pp. 227-233. doi:10.1016/j.epsr.2006.02.016

[76] H. Shayeghi, M. Mahdavi and A. Bagheri, "Discrete PSO Algorithm Based Optimization of Transmission Lines Loading in TNEP Problem," Energy Conversion and Management, Vol. 51, 2010, pp. 112-121. doi:10.1016/j.enconman.2009.08.030

[77] Z. Y. Dong, K. P. Wong, K. Meng, F. Luo, F. Yao and J. Zhao, "Wind Power Impact on System Operations and Planning” Proceedings of IEEE PES General Meeting 2010. doi:10.1109/PES.2010.5590222

[78] G. Chen, D. J. Hill and Z. Y. Dong, “Tansmission Network Expansion Planning with Wind Energy Integration: A Stochastic Programming Model”, IEEE PES General Meeting, San Diego, CA, USA 22-26 May 2012.

[79] G.Y. Yang, Z. Y. Dong and K. P. Wong, "Differential Evolution with Niche Method in the Application of Power System Planning”, (Chapter 3) in Z. Xu and Z. Fan edit, Evolutionary Computing for Intelligent Power System Optimization and Control, Nova Publishers, series in Energy Science, Engineering and Technology, published 4th Quarter, 2010.

[80] J. H. Zhao, Z. Y. Dong, J. Foster and K. P. Wong, "Flexible Transmission Network Planning Considering Distributed Generation Impacts," IEEE Transactions on Power Systems, Vol. 24, No. 1, 2009, pp. 479-488. 